\title{
İkiz Açık Hipotezinin Geçerliliği: Türkiye Örneği (1995-2013)
}

\author{
Öğr. Gör. Dilek ŞAHİN \\ Cumhuriyet Üniversitesi, Yıldızeli MYO, SiVAS
}

\begin{abstract}
ÖZET
İkiz açıklar hipotezi, bütçe açıkları ile cari açıklar arasında bir ilişki olduğunu ileri sürmektedir. Bu çalışmada 1995:1 -2013:1 dönemlerinde Türkiye'nin bütçe açı̆̆ ve cari işlemler açı̆̆l arasındaki ilişkinin incelenmesi amaçlanmaktadır. Yapılan VAR analizi sonucu Türkiye'de bütçe açıklarının cari açıklara yol açmadığı dolayısıyla ikiz açıklar hipotezinin geçerli olmadiğı sonucuna ulaşılmıştır.
\end{abstract}

Anahtar Kelimeler: Bütçe Açı̆̆ı, Cari Açık, İkiz Açık Hipotezi.

JEL Sinıflaması: E0O, H0O, H6

2013)

Validity of the Twin Deficits Hypothesis: The Case of Turkey (1995-

\section{ABSTRACT}

Twin deficit hypothesis is a phenomen came up with there is a relation between budget deficit and current account deficit. This study aim to the relationship between the budget deficit and the current account deficit by using the data period 1995: 1-2013: 1 in Turkey. The result of VAR analysis show that budget deficit in Turkey does not cause current account deficits so it was concluded that the twin deficits hypothesis is not valid.

Key Words : Budget Deficit, Current Acount Deficit, Twin Deficit Hypothesis.

JEL Classification: EOO, HOO, H6

\section{GİRIŞ}

1980’lerin başlarında ABD önemli büyüklükte bir bütçe açı̆̆ı problemi ile karşı karşıya kalmıştır. Oluşan bütçe açığı ekonomik etkinliğin azalmasına neden olmuştur. Sonrasında bütçe açığına cari işlemler dengesinde meydana gelen yüksek açıklar eşlik etmiştir. Bu durum iki açık arasındaki ilişkiyi ifade eden " ikiz açık" tartışmasını başlatarak ekonomi politikalarının önemli bir konusu haline gelmiştir. Türkiye ekonomisinde kamu sektörü 1930'lardan itibaren hem üretici hem de tüketici olarak önemli rol oynamıştır. 1980'li y1llardan itibaren uygulanan özelleştirme programlarına ve alınan önlemlere rağmen cari işlemler açığı ve bütçe açığı ülkemizde sorun olmaya devam etmiştir.

İktisat literatüründe bütçe açıkları ile cari işlemler açıkları arasındaki ilişkiyi açıklayan "İkiz Açıklar Hipotezine" göre bu iki açık arasında pozitif bir ilişki bulunmaktadır. Bu hipotezi Keynesyen Geleneksel Teori ve Ricardian Denkliği hipotezi farklı şekilde açıklamaktadır. Geleneksel Keynesyen teoriye göre bütçe açıkları ile cari işlemler açıkları arasında kuvvetli bir korelasyon bulunurken; Ricardian Denkliği hipotezinde bütçe açıkları ile cari işlemler açıkları arasında bir korelasyon bulunmamaktadır bu nedenle ikiz açıklar hipotezi 
geçersiz kabul edilmektedir. Bu çalışmanın temel amacı, bütçe ve cari işlemler açığ 1 ilişkisini teorik ve uygulamalı çerçevede 1995:1 ve 2013:1 dönemi verileri ile Türkiye ekonomisi açısından değerlendirmektir. İlk olarak ikiz açıklar hipotezine ilişkin teorik çerçeve ele alınacak ve iki karşıt teori olan Geleneksel Yaklaşım ve Ricardocu Denklik Hipotezi açıklanacaktır. Sonraki bölümde, ikiz açıklar hipotezine ilişkin uygulamalı literatüre değinilecek ve son olarak ampirik analiz sonuçlarına yer verilecektir.

\section{II. İkiz Açıklar Hipotezinin Teorik Çerçevesi}

Bir ülkede makroekonomik dengenin sağlanmasında iç ve dış dengeyi temsil eden bütçe açıkları ile cari açık iki önemli göstergedir. İkiz açık hipotezi, bütçe açığı ile cari açık arasında kuvvetli bir korelasyon olduğunu iddia etmektedir. Ekonomide bir dış ticaret denkliği, dış ticaret açığı veya bütçe fazlası olabilir yani bu iki olgu eş zamanlı ortaya çıkabilir (Kılavuz ve Dumrul, 2009: 240). İkiz açık hipotezinin teorik çerçevesi milli gelir üzerinden oluşmaktadır. Hipotezi daha iyi analiz edebilmek için milli gelir tanımının dikkatli incelenmesi gerekmektedir. $\mathrm{Bu}$ yaklaşıma göre milli gelire ilişkin denklemlerden hareketle ikiz açıklar hipotezi(1) numaralı eşitlikteki gibi açıklanabilir.

$$
Y=C+I+G+(X-M)
$$

Cari işlemler açığının (CA) dış ticaret açığına bağlı olduğu varsayımı ile, (1) numaralı eşitlikte, (Y) GSMH'yı; (C) tüketim harcamalarını; (I) yatırım harcamalarını;(G) Kamu harcamaların1; (X) ihracatı ve (M) ithalat1 göstermektedir. Cari işlemler açığ 1 , ihracat ve ithalat arasındaki fark olarak ele alınmakla birlikte (1) numaralı denklemde bu fark (X-M) yerine CA yazılarak eşitliğin sol tarafına çekilirse (2) ve (3) numaralı eşitlik elde edilmektedir.

$$
\begin{aligned}
& Y=C+I+G+C A \\
& C A=Y-(C+I+G)
\end{aligned}
$$

Açık ekonomilerde ulusal tasarruf (S), milli gelirin özel ve kamu kesimi tarafından tüketilmeyen kısmına eşittir. Buradan hareketle, ulusal tasarruf (S), (4) numaralı denklemdeki gibi ifade edilebilir:

$$
S=Y-C-G+C A
$$

Tasarrufların (S) yatırımlara (I) eşit olduğu varsayımından yola çıkılarak (5) numaralı denklem yazılabilir:

$$
Y-C-G=I
$$

(5) nolu denklemden yola çıkılarak ulusal tasarrufun, yatırım ve cari işlemler açığı toplamına eşit olduğunu gösteren (6) numaralı eşitliğe ulaşılabilir.

$$
S=I+C A
$$

Ulusal tasarruflar $(\mathrm{S})$, özel kesim tasarrufları $\left(\mathrm{S}^{\mathrm{p}}\right)$ ve kamu kesimi tasarruflarının $\left(\mathrm{S}^{\mathrm{g}}\right)$ toplamından oluşmaktadır.

$$
S=S^{p}+S^{g}
$$

(7) nolu eşitlikte $\left(S^{p}\right)$ vergi sonrası gelirin yani harcanabilir gelirin tüketilmeyen kısmını yansıtmaktadır. 
Dolayısıyla $S^{p}=Y-T-C$ 'dir.

$\left(S^{g}\right)$ ise, kamu tarafindan elde edilen vergi gelirleri ve kamunun gerçekleştirdiği harcama arasındaki farkı göstermektedir.

$$
S^{g}=T-G
$$

İlgili tanımlamalardan sonra ulusal tasarruf eşitliği şu şekilde yeniden yaz1labilir:

$$
\begin{aligned}
& S=S^{p}+S^{g}=I+C A \\
& S^{p}=I+C A-S^{g}=I+C A-(T-G)=I+C A+(G-T) \\
& S^{p}=I+X-M+G-T
\end{aligned}
$$

bu denklemi yeniden düzenlersek eğer eşitlik

$$
(X-M)=S^{p}-I-(G-T) \text { haline dönüşür. }
$$

Burada, $(X-M)$ dış ticaret açığını ; $(G-T)$ bütçe açı̆̆ını temsil etmektedir. Son denklem cari işlemler açığı ve bütçe açığı arasındaki bağlantıyı araştırmak amacıyla teorik bir çerçeve sunmaktadır.

\section{III. İkiz Açıklar Hipotezine Yönelik Yaklaşımlar}

İkiz açıklar hipotezine yönelik iki genel yaklaşım bulunmaktadır. Bunlardan ilki hipotezi destekleyen Geleneksel Keynesyen Yaklaşım, diğer ise hipotezin geçerliliğini reddeden Ricardocu Denklik Hipotezi'dir. İkiz açıklar hipotezine ilişkin iktisat literatüründeki bu yaklaşımların ele alınması, bütçe açığıcari açık ilişkisinin açıklanmasına yardımcı olmaktadır.

\section{A. Geleneksel Yaklaşım}

Geleneksel yaklaşım bütçe açıkları ile cari işlemler açıkları arasında güçlü bir ilişki olduğunu savunmaktadır. İkiz açıklar hipotezi Keynesyen Teoriye dayanmakla birlikte, bu yaklaşıma göre söz konusu açıklar arasında kuvvetli bir ilişki bulunmaktadır. Geleneksel yaklaşım iki değişken arasındaki ilişkiyi açıklarken iki çıkarımda bulunmaktadır. Bunlardan ilki bütçe açıkları ile cari açık arasında pozitif bir ilişkinin bulunduğu, ikincisi ilişkinin yönünün bütçe açıklarından cari açıklara doğru olduğu yönündedir (Alkswani, 2000: 4). Bu yaklaşım ikiz açıklar hipotezini Keynesyen gelir harcama yaklaşımı ve MundelFleming modeli ile açıklamaktadır.

Mundell- Fleming modelinde, bütçe açıklarının dış açıkları artırıcı etkisi bulunmaktadır. Keynesyen Gelir-Harcama görüşüne göre, kamu harcamalarının artması ya da vergi gelirlerinin azalması sonucu artan bütçe açıkları, üretim ve tüketime pozitif etkide bulunarak ulusal geliri artırmaktadır (Altunöz, 2014: 428).

Keynesyen Gelir-Harcama yaklaşımında, kamu harcamalarının artırılması ya da vergilerin azaltılmasıyla kamu bütçe açıklarında bir artışın ortaya çıkması sonucu milli gelir uyarılmaktadır. Bu durum ithalatı artırarak cari açığı ortaya çıkarmaktadır. Böylece bütçe açıkları ile cari açıklar aynı yönde hareket ederek ikiz açıklara neden olmaktadır (Kör, 2012: 65). Keynesyen gelir-harcama modelinde tasarruflar gelire bağlı bir büyüklüktür ve faiz oranına bağlı olarak değişmez. $\mathrm{Bu}$ durumda, devlet genişletici maliye politikası uygulayarak harcamalarını artırır ya da vergileri düşürürse yurt içi toplam tasarrufta, devletin 
tasarruf ettiği miktar azalmaktadır. Böylece ulusal tasarrufta azalmaya meydana gelmektedir. Ekonomide dengeye ulaşılabilmesi için tasarruflardaki azalma kadar cari açık gerçekleşmektedir. Aynı durum devletin vergi indirimine giderek genişletici maliye politikası uygulaması durumunda da geçerlidir. Vergi indirimi durumunda bireylerin harcanabilir gelirlerinde artış olmakta ve tüketim artarak tasarruf azalmaktadır. Tasarrufların yatırımları karşılayamaması durumunda ise cari açık ortaya çıkmaktadır.

Mundell-Fleming Modeli: Kamu harcamalarının kamu gelirleriyle karşılanamadığı bir ekonomide kamu harcamalarındaki bir artış milli gelirde artışa neden olacaktır. Bu artış yurtiçi toplam talep ve faiz haddinde artışa neden olacaktır. Uluslararası sermaye haraketliliğinin olduğu bir ortamda faiz hadlerindeki artış yurtdışından yurt içine doğru sermaye akımına neden olacaktır. Artan sermaye akımı ile yerli paraya olan talebin artmasıyla yurt içi para değer kazanacak ve döviz kurunda düşüş yaşanacaktır. Kurdaki düşüş ise yurtiçi malları yurtdışı mallar karşısında görece pahalı bir duruma getirecektir. Bu durumda hem artan gelir seviyesiyle yurtiçinden yurtdışı mallara olan talep artarken, hem de yurtdışından görece pahalılaşan yerli mallara olan talep azalacak ve net ihracat düşecektir. Bu da cari dengenin acık vermesine neden olacaktır.

\section{B. Ricardocu Denklik Yaklaşımı}

Ricardocu Denklik yaklaşımı, bütçe açıkları ile cari açıklar arasında herhangi bir ilişki bulunmadığını, diğer bir ifadeyle ikiz açıklar hipotezinin geçersizliğini savunmaktadır. Bu yaklaşımda dış ticaret dengesi, faiz oranları ve yatırım miktarları bütçe açığındaki değişmelerden etkilenmemektedir.

$\mathrm{Bu}$ yaklaşımda hükümetler tarafından vergi indirimine gidildiğinde, oluşacak bütçe açığı cari işlemler bilançosunu etkilemeyecektir. Sabit kamu harcamaları ve borçlanmada herhangi bir kısıtlamaya gidilmediği varsayımı altında uygulanacak bir vergi indirimi ileride bir vergi artırımı ile giderileceğinden cari vergilerdeki azalma planlanan tasarruf düzeyinde bir etkiye sahip olmayacaktır. Çünkü bütçe açıkları ulusal tasarruf düzeyi ile ilişkisizdir ve özel tasarruflardaki artış bütçe açıklarını dengeleyerek etkisiz hale getirmektedir. $\mathrm{Bu}$ nedenle bütçe açıklarının ekonomi üzerinde herhangi bir etkisi olmayacaktır (Uğur ve Karatay, 2009: 117).

Ricardocu yaklaşıma göre kamu tasarruflarında bir azalma yani cari bütçe açı̆̆ı, özel tasarrufta aynı miktarda bir artışa yol açar ve bu nedenle ulusal tasarrufta bir değişme olmaz. Planlanan ulusal tasarruflar değişmediği için kapalı bir ekonomide reel faiz oranlarının, planlanan toplam tasarrufla ve yatırım talebini eşitlemek için yükselmesine gerek yoktur. Bu nedenle yatırımlar üzerinde kamu borç yükünün hiçbir etkisi yoktur. Açık bir ekonomide ise özel tasarruflar diş borçlanma ihtiyacını ortadan kaldıracak kadar yükseleceği için bütçe açığı cari işlemler açı̆̆ına sebebiyet vermeyecektir (Barro, 1989: 38).

\section{IV. İkiz Açıklar Hipotezi Üzerine Yapılmış Ampirik Çalışmalar}

İktisat literatüründe bütçe açı̆̆ı ve cari işlemler açığı arasındaki ilişki çok sayıda araştırmacı tarafından farklı modeller ve yöntemler kullanılarak analiz edilmiştir. Burada literatürde yer alan bazı çalışmalara yer verilmiştir. 
Utkulu (2003), Türkiye'de 1950-2000 y1lları arasında bütçe açıkları ile cari açıklar arasındaki uzun dönemli ilişkiyi durağanlık testi, eşbütünleşme testi ve hata düzeltme modelini kullanarak araştırmıştır. Çalışılan veri seti zaman serisi olduğu için, zaman serilerinin gerektirdiği testler yapılarak söz konusu dönemde bütçe açıkları ile dış ticaret açıkları arasındaki kuramsal bağın varlığının deneysel olarak da iki yönlü olduğu sonucuna varılmıştır.

Aksu ve Başar (2005), 1989-2003 yılları arasında bütçe giderleri/bütçe gelirleri ve ithalat/ihracat oranları açıklayıcı değişken olarak belirlenmiş ve aylık veriler kullanılmıştır. VAR analizi uygulamasında, bütçe açıklarının dış ticaret açıklarını etkilediği ancak ters yöndeki etkilemede bir zaman boşluğu oluştuğu diğer bir ifadeyle diş ticaret açığındaki artışın bütçe açığına olan etkisinin bir müddet sonra ortaya çıktığ 1 sonucuna ulaşılmıştır.

Ünsal (2006), 1980-2004 dönemi verilerini kullanarak Granger nedensellik testi ve eşbütünleşme analizi yapmıştır. Granger nedensellik testine göre, ödemeler bilançosu açıklarından kamu açıklarına doğru bir nedensellik ilişkisi ortaya konulurken, eşbütünleşme analizi sonuçlarına göre de iki değişken arasında kısa ve uzun dönemde bir denge ilişkisi olduğu sonucuna ulaşılmıştır.

Yanık (2006), 1988-2005 dönemi için çeyreklik veriler ile bütçe açıkları, cari açık, ulusal gelir, reel faiz oranları ve reel kur oranını içeren VAR modeli oluşturarak, Granger nedensellik testi ile devam eden hata düzeltme modeli ve etki-tepki analizleri yapmıştır. Bütçe açıkları ve cari açıkların periyodik hareketin tersine hareket ettikleri sonucuna ulaşılmıştır. Çalışmada yürütülen EngleGranger ve Johansen eşbütünleşme testlerinin bulguları, ikiz açıkların ters yönlü hareket ettiği varsayımını desteklemiştir.

Gök ve Altay (2007), 1988-2005 dönemi için aylık veriler ile bütçe açıkları ve cari açıklar arasındaki ilişkiyi zaman serisi yaklaşımı kullanarak makroekonomik değişkenler arasında uzun dönemli ilişkinin varlığını eşbütünleşme testleri ile sınamışlardır. Değişkenlerin birbirleri üzerine etkilerinin gözlenebilmesi amacıyla vektör otoregresif model yöntemi yardımıyla etki-tepki analizleri yapmışlardır. Çalışmanın sonucunda, İkiz Açıklar Hipotezi'nin söz konusu dönem için uzun dönemde geçerli olmadığ 1 ancak, kısa dönem için geçerli olduğu sonucuna ulaşmışlardır.

Kılavuz ve Dumrul (2012), bütçe açığı ile cari işlemler açı̆̆ı arasındaki ilişki 2006:01-2010:12 verileri ile sınır testi, VAR analizi ve Granger Nedensellik testi kullanılarak uygulamalı olarak test edilmiştir. Çalışmada cari işlemler açığının dış ticaret açığına eşit olduğu varsayılmıştır. Sınır testi yaklaşımına göre uzun dönemde söz konusu iki açık arasında bir ilişki olmadığ1 bulgusuna ulaşılmıştır. Kısa dönemli dinamiklerin ortaya konulması için yapılan VAR analizi sonuçlarına göre bütçe açığı ve cari işlemler açığı arasında iki yönlü ilişki olduğu görülmüştür.

Kör (2012), çalışmada yapılan ekonometrik analizlerde de Ricardocu Denklik Hipotezini destekleyen sonuçlara ulaşılmıştır. Durağan bütçe açı̆̆ı/GSYİH, büyüme oranı ve trend durağan cari açık/GSYİH ve reel faiz oranı serileri ile cari açı̆̆ın yaz aylarındaki turizm gelirlerinden kaynaklı mevsimselliği 
de dikkate alınarak oluşturulan, içsel bağıntı sorunu olmayan VAR modelleri çerçevesinde yapılan Granger nedensellik ve etki - tepki analizleri sonucunda bütçe açıklarından cari açıklara cari açıklardan bütçe açıklarına doğru bir nedensellik bulunamamıştır.

İyidoğan ve Erkam (2013), 1987-2005 dönemi için bütçe dengesi ile cari işlemler dengesi arasındaki nedensellik ilişkisini ortaya koymak amacıyla Granger nedensellik analizi kullanılmıştır. Elde edilen sonuçlar, ikiz açıklar hipotezinin geçerli olmadığını göstermiştir. Bunun aksine Türkiye'de cari işlemler dengesindeki gelişmelerin bütçe dengesi üzerinde etkili olduğu sonucuna ulaşılmıştır.

Altunöz (2014), çalışmada 2000:1 -2013:3 dönemlerine ait bütçe açığ 1 ve car işlemler açığı arasındaki ilişki incelenmiştir. Bu amaçla Pesaran ve diğerleri tarafından geliştirilen sınır testi yaklaşımı uygulanmıştır. Ekonometrik analiz sonuçlarına göre uzun dönemde bütçe açığı ile cari işlemler arasında bir ilişkinin olmadığı, kısa dönemde bütçe açığı ile cari işlemler açığı arasında pozitif ve güçlü bir ilişki olduğu anlaşılmıştır.

\section{Veri Seti, Ekonometrik Yöntem, Uygulama Sonuçları ve Değerlendirmeler}

Bu çalışmada yapılan teorik açıklamalar çerçevesinde, 1995:1- 2013:1 dönemi için çeyreklik veriler kullanılarak ekonometrik uygulama yapılmıştır. Veri ve kaynaklar tablo 1'de verilmiştir. Çalışmada kullanılan $B D, C D, K R, R F$ değişkenler, kolaylık sağlaması açısından yüzde olarak ifade edilerek elde edilen oranlar 100 ile çarpılmıştır. Mevsimsel etkiler barındırdığı gözlenen bütçe dengesi ve cari dengeye ilişkin seriler Census X12 mevsimsellik filtresine tabi tutularak mevsimsellikten arındırılmış ve modelde sırasıyla BD_SA ve CD_SA olarak isimlendirilmiştir.

Tablo 1. Modelde Kullanılan Veriler

\begin{tabular}{|l|l|l|}
\hline Değişken & Tanımlama & Kaynak \\
\hline CD_SA & Cari Denge /GSYİH & TCMB \\
\hline BD_SA & Bütçe Dengesi /GSYİH & TCMB, Maliye Bakanlığ 1 \\
\hline KR & Reel Döviz Kuru Endeksi & TCMB \\
\hline RF & Reel Faiz Oranı & TCMB, Hazine \\
\hline
\end{tabular}

Çalışmada kullanılan model; $C A_{t}=\beta_{0}+\beta_{1} B A+\beta_{2} K R+\beta_{3} R F+u_{t}$ şeklindedir. Çalışmada ekonometrik yöntem olarak zaman serisi yaklaşımı kullanılmıştır. Çalışmada uygulanan ekonometrik analiz iki aşamadan oluşmaktadır. İlk aşamada, kullanılan değişkenlerin durağanlığ 1 birim kök testleri ile analiz edilmiştir. Durağan olmayan zaman serisi verileri kullanılarak oluşturulan modellerde sahte regresyon yaşanması olasılığ 1 nedeniyle, tahmin sonuçlarının sahte bir ilişkiyi yansıtması söz konusu olabilir. Durağan serilerin zaman içerisinde ortalaması, varyansı ve kovaryansı değişim göstermemektedir. Durağan olmayan değişkenlerde $t, Z$ ve $F$ dağılımları kullanılamaz ve dolayısıyla pek çok standart hipotez kullanılamaz duruma gelmektedir. Zaman serilerinin durağanlıkları çeşitli yöntemlerle sınanmaktadır. Son zamanlarda yoğun olarak 
ADF (Augmented Dickey-Fuller) testleri birim kok sinamasında kullanılmaktadır. $\mathrm{Bu}$ çalışmada da değişkenlerin durağanlık araştırması ADF testi ile yapılmıştır. Bir Yt serisinin birim kökü varlığı araştırılırken aşağıdaki hipotez ve ADF tipi regresyon denklemi kullanılmaktadır.

ADF birim kök testi için söz konusu hipotez şu şekilde ifade edilmektedir:

$\mathrm{H}_{0}=$ Seriler durağan değil, birim kök var.

$\mathrm{H}_{\mathrm{A}}=$ Seriler durağan, birim kök yok .

ADF testi için kurulan sabitli ve sabitli-trendli modeller şu şekilde gösterilmektedir:

$$
\begin{aligned}
& \Delta y_{t}=\beta+\delta y_{t-1}+\sum_{i=1}^{p} \phi i \Delta y_{t-i}+\varepsilon_{t} \\
& \Delta y_{t}=\beta+\alpha T+\delta y_{t-1}+\sum_{i=1}^{n} \phi \Delta y_{t-i}+\varepsilon_{t}
\end{aligned}
$$

\begin{tabular}{|c|c|c|c|c|}
\hline \multirow{3}{*}{ Değișkenin Adı } & \multicolumn{2}{|c|}{ ADF Birim Kök Testi } & \multirow{2}{*}{\multicolumn{2}{|c|}{$\begin{array}{l}\text { 1.Fark Değeri } \\
\text { (Sabitli- Trendli) }\end{array}$}} \\
\hline & \multicolumn{2}{|c|}{$\begin{array}{lll}\text { Düzey } & \text { Değerleri } & \text { (Sabitli- } \\
\text { Trendli) } & & \\
\end{array}$} & & \\
\hline & Test İstatistiği & Kritik Değer & Test İstatistiği & Kritik Değer \\
\hline BD_SA & -3.11 & -3.47 & $-13.70^{*}$ & -3.47 \\
\hline CD SA & $-7.95 *$ & -3.47 & & \\
\hline $\mathrm{RF}$ & $-3.74 *$ & -3.47 & & \\
\hline KUR & -3.44 & -3.47 & $-8.92 *$ & -3.47 \\
\hline
\end{tabular}

Tablo 2. ADF (Genişletilmiş Dickey-Fuller) Birim Kök Testi

*Kritik değer olarak \%5 anlamlılık düzeyi esas alınmıştır.

Tablo 2'de ADF kök testi sonuçlarına yer verilmiştir. Tablo 2'de görüldüğü üzere, cari denge ve reel döviz kuru değişkeni sabitli-trendli modele göre $\% 5$ anlamlılık düzeyinde düzey değerinde durağan $\mathrm{I}(0)$ bulunmuştur. Bütçe dengesi ve kur değişkeninin ise birinci derecede durağan olduğu I(1) görülmüştür.

Seriler arasında kısa dönemli ilişkileri gözlemlemek için VAR analizi yapılmıştır. VAR analizinde kullanılan değişkenler durağan oldukları seviyede analize dâhil edilmektedirler.

VAR modeli ile serilerin durağan formlarının kendilerinin ve diğer değişkenlerin gecikme değerlerinin üzerine vektorel formda regresyonu yapılır. $\mathrm{Bu}$ modelin en büyük avantajı kullanılan değişkenler arasında içsel ve dışsal ayrımı yapmaksızın tüm değişkenlerin diğer değişkenler üzerindeki etkilerini ortaya koyabilmesidir.

Var analizinde ilk olarak uygun gecikme uzunluğu belirlenmeye çalışılmış ve buna ilişkin açıklamalar tablo 3'de gösterilmiştir. 
D. Şahin / İkiz Açck Hipotezinin Geçerliliği: Türkiye Örneği (1995-2013)

Tablo 3. Var Analizi İçin Uygun Gecikme Uzunluğunun Belirlenmesi

\begin{tabular}{|l|l|l|l|l|l|}
\hline Gecikme & LR & FPE & AIC & SIC & HQ \\
\hline 0 & NA & 0.015145 & 7.161415 & 7.293039 & 7.213499 \\
\hline 1 & 202.6925 & $0.000930^{*}$ & $4.369793^{*}$ & $5.027910^{*}$ & $4.630212^{*}$ \\
\hline 2 & 6.606248 & 0.001345 & 4.733504 & 5.918115 & 5.202258 \\
\hline 3 & 21.44670 & 0.001477 & 4.813955 & 6.525060 & 5.491043 \\
\hline 4 & 10.87556 & 0.001965 & 5.074056 & 7.311654 & 5.959479 \\
\hline
\end{tabular}

Not: * uygun gecikme uzunluğunu göstermektedir.

Tablo 3'den de görüldüğü üzere, AIC, SIC, HQ,FPE ve LR bilgi kriterine göre uygun gecikme uzunluğu 1 olarak belirlendikten sonra, söz konusu gecikme uzunluğuna göre modelde otokorelasyon sorunun olup olmadığı Lagrange Çarpanı (L-M) testi ile araştırılmış ve 10 gecikme için yapılan analizde modelde otokorelasyon sorunu olmadığ 1 bulgusuna ulaşılmış, diğer bir ifadeyle yapılan testte içsel bağıntı sorununa rastlanmamıştır. Belirtilen durum Tablo 4'te gösterilmiştir.

Tablo 4 . L-M Otokorelasyon Test Sonuçları

\begin{tabular}{|l|c|c|}
\hline Gecikme Uzunluğu & L-M İstatistiği & Prob. \\
\hline 1 & 33.03784 & 0.0073 \\
\hline 2 & 22.45597 & 0.1291 \\
\hline 3 & 17.74049 & 0.3393 \\
\hline 4 & 18.71566 & 0.2837 \\
\hline 5 & 13.98208 & 0.6000 \\
\hline 6 & 7.450613 & 0.9636 \\
\hline 7 & 22.16158 & 0.1381 \\
\hline 8 & 24.15564 & 0.0862 \\
\hline 9 & 7.768123 & 0.9555 \\
\hline 10 & 17.39997 & 0.3602 \\
\hline 11 & 12.28701 & 0.7240 \\
\hline 12 & 24.37402 & 0.0816 \\
\hline
\end{tabular}

Ele alınan modelde değişen varyans sorunu olup olmadığ 1 ise, White testiyle araştırılmıştır. Analiz sonuçları modelde değişen varyans sorunu olmadığını göstermiş ve test sonuçlarına Tablo 5'de yer verilmiştir.

Tablo 5. White Değișen Varyans Test Sonucu

\begin{tabular}{|l|l|l|}
\hline Chi-sq & Serbestlik Derecesi & Olasilık \\
\hline 137.1934 & 160 & 0.9038 \\
\hline
\end{tabular}

VAR modelinin bütün olarak durağanlığının test edilmesi amacıyla ters AR kökleri incelenmiştir. Şekil 1'de görüldüğü üzere, modele ilişkin ters AR kökleri birim çemberin içerisindedir. Bu durumda VAR modelinin bir bütün olarak durağan olduğunu söyleyebiliriz. 
Şekil 1. VAR Sisteminin Karakteristik Kökleri

\section{Inverse Roots of AR Characteristic Polynomial}

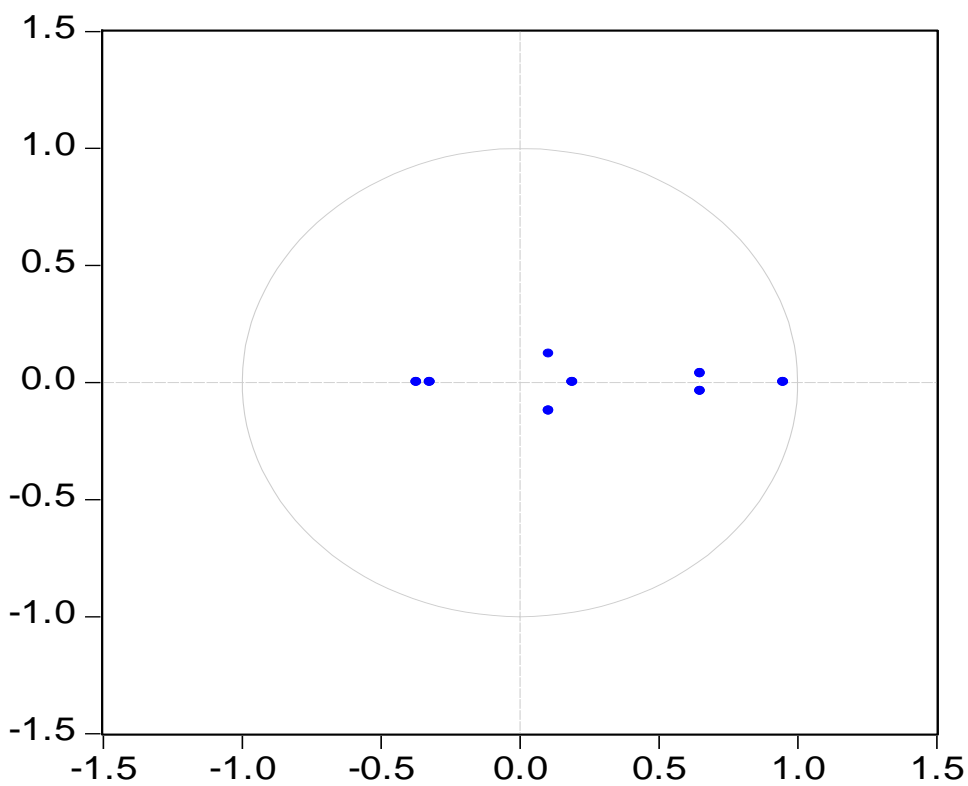

$\mathrm{Bu}$ çalışmada ayrıca, bütçe açığı, reel döviz kuru ve reel faiz değişkenlerinin cari işlemler açığı değişkeni arasındaki nedensellik analizi için Granger nedensellik testi uygulanmıştır. Granger nedensellik testi ile modelde yer alan bağımsız değişkenlerin grup halinde sıfıra eşit olup olmadığı test edilmektedir. Burada;

$\mathrm{H}_{0}=$ Nedensellik ilişkisi yoktur.

$\mathrm{H}_{\mathrm{A}}=$ Nedensellik ilişkisi vardır şeklinde ifade edilmektedir.

Tablo 6. Granger Nedensellik /Blok Dışsallık Sinaması

\begin{tabular}{|l|l|l|}
\hline Nedensellik Yönü & Olasılık & Nedensellik \\
\hline Cari Denge $\longrightarrow$ Bütçe Dengesi & 0.8183 & Yok \\
\hline Bütçe Dengesi Cari denge & 0.7996 & Yok \\
\hline Reel Faiz Bütçe Dengesi & 0.2114 & Yok \\
\hline Reel Faiz $\longrightarrow$ Cari Denge & 0.1498 & Yok \\
\hline Kur $\longrightarrow$ Bütçe Dengesi & 0.0070 & Var \\
\hline Kur Cari Denge & 0.0012 & Var \\
\hline
\end{tabular}


Tablo 6'da Granger nedensellik test sonuçlarına yer verilmiştir. Yapılan Granger nedensellik testi sonuçlarına göre, bütçe dengesinden cari dengeye ve cari dengeden bütçe dengesine doğru bir nedensellik ilişkisine rastlanmamıştır. Yine reel faizden bütçe dengesine ve cari dengeye doğru nedensellik ilişkisinin olmadığ1 görülmüştür. Kurdan bütçe dengesi ve cari dengeye doğru nedensellik ilişkisinin bulunduğu görülmektedir.

\section{SONUÇ}

1980'lerin başında Amerika'da oluşan yüksek bütçe açıları ve ardından buna eşlik eden cari işlemler açığı, ikiz açık olgusunu gündeme taşımıştır. Ricardocu yaklaşımı iki açık arasında bir ilişki bulunmadığını iddia ederken Keynesyen Geleneksel Görüş, bütçe açığı ile cari işlemler açığı arasında nedensellik bulunduğunu savunmaktadır.

Bu çalışmada, 1995:1 ve 2013:1 dönemlerini kapsayan çeyreklik veriler kullanılmıştır. Uygulama kısmına geçilmeden önce teori ve literatür araştırması yapılmıştır. Uygulama kısmında VAR yöntemi izlenmiştir. Değişkenlerin durağanlığı ADF birim kök testi ile sınanmış, modelin uygunluğu tespit edilmiş ve Granger nedensellik analizi yapılmıştır. Çalışmada sonuç olarak, bütçe dengesi ile cari denge arasında bir ilişki görülmemiştir dolayısıyla Türkiye için ele alınan dönemler itibariyle ikiz açık hipotezinin geçerli olmadığg görülmüştür. Çalışmada ayrıca reel faizin cari denge ve bütçe dengesi üzerinde etkisinin olmadığ1 ancak kurun cari denge ve bütçe dengesi üzerinde etkili olduğu sonucuna ulaşı1mıştır.

\section{Kaynaklar}

Aksu, Hayati ve Selim Başar (2005), "İkiz Açıklar Hipotezinin Türkiye Acısından Araştırılması”. İktisat Işsletme ve Finans, 20(234), 109-114.

Alkswani, Mamdouh. A (2000), “The Twin Deficit Phenomenon in Petroleum Economy : Evidence from Saudi Arabia”. Seventh Annual Conference, Economic Research Forum, 1-25.

Altunöz, Utku (2014), "İkiz Açık Hipotezinin Geçerliliği Sınır Yöntemiyle Sınanması: Türkiye Örneği”. Adiyaman Üniversitesi Sosyal Bilimler Enstitüsü Dergisi, 7(17), 426-446.

Azgün, Sabri (2012), "Twin Deficit Hypothesis : Evidence From The Turkish Economy”. Doğuş Üniversitesi Dergisi, 13(2), 189-196.

Barro, Robert .J (1989), "The Ricardian Approach to Budget Deficits". Journal of Economic Perspectives, 3(2), 37-54.

Gök, Barış ve Oğuzhan Altay (2007), “Türkiye'de İkiz Açılar Hipotezi 1989-2005”. TİSK Akademi Dergisi, 1(2), 186-196.

İyidoğan, Pelin ve Serkan Erkam (2013), “İkiz Açıklar Hipotezi: Türkiye İçin Ampirik Bir İnceleme (1987-2005)", Pamukkale Üniversitesi Sosyal Bilimler Enstitüsü Dergisi, 15, 39-48.

Kılavuz, Emine ve Yasemin Dumrul (2012), “ İkiz Açıklar Hipotezinin Geçerliliği: Teori ve Uygulama”. Atatürk Üniversitesi İktisadi ve İdari Bilimler Dergisi, 26(3), 239-258.

Kör, Esma (2012), “İkiz Açıklar Hipotezi : Türkiye Örneği”. Ankara Üniversitesi Sosyal Bilimler Enstitüsü İktisat ABD Yayınlanmamış Yüksek Lisans Tezi.

Uğur, Ahmet A. ve Pelin Karatay (2009), "İkiz Açılar Hipotezi: Teorik Çerçeve ve Hipoteze Yönelik Yaklaşımlar”. Sosyo-Ekonomi, 102-122.

Uğurlu, Erginbay ve Recep Düzgün (2009), “ Türkiye Ekonomisi İçin Ricardo Eşitliği Hipotezinin Test Edilmesi”. Marmara Üniversitesi İktisadi ve İdari Bilimler Fakültesi Dergisi, 26 (1), 99-166. 
Utkulu, Utkulu (2003), "Türkiye'de Bütçe Açıkları ve Dış Ticaret Açıkları Gerçekten İkiz mi? Koentegrasyon ve Nedensellik Bulguları". Dokuz Eylül Üniversitesi İIBF Dergisi, 18(1), $45-61$.

Ünsal, Hilmi (2006), "Kamu Açıkları ile Ödemeler Bilançosu Açıkları Arasındaki Etkileşim: 1980 Sonras1 Türkiye Örneği”. Gazi Üniversitesi Sosyal Bilimler Enstitüsü Doktora Tezi.

Yanık, Yeliz (2006), The Twin Deficit Hypothesis: An Empirical Investigation. Orta Doğu Teknik Üniversitesi İktisat Ana Bilim Dalı Yüksek Lisans Tezi. 